\title{
1 Activation of oral epithelial EphA2-EFGR signaling by Candida albicans virulence factors
}

2

3 Short title: C. albicans virulence factors and host receptors

4 Marc Swidergall ${ }^{1,2,3 *}$, Norma V. Solis ${ }^{1,2}$, Nicolas Millet ${ }^{1,2}$, Manning Y. Huang ${ }^{4 \#}$, Jianfeng Lin, ${ }^{1,2}$

5 Quynh T. Phan ${ }^{1,2}$, Michael D. Lazarus ${ }^{1}$, Zeping Wang ${ }^{1 \S}$, Aaron P. Mitchell ${ }^{5}$, Scott G. Filler ${ }^{1,2,3 *}$

7 Affiliations

$8{ }^{1}$ Division of Infectious Diseases, Harbor-UCLA Medical Center, Torrance, California 90502, USA

$9 \quad{ }^{2}$ Institute for Infection and Immunity, The Lundquist Institute for Biomedical Innovation at Harbor-

10 UCLA Medical Center, Torrance, California 90502, USA

$11{ }^{3}$ David Geffen School of Medicine at UCLA, Los Angeles, California 90024, USA

$12{ }^{4}$ Department of Biological Sciences, Carnegie Mellon University, Pittsburgh, Pennsylvania 15213,

13 USA

$14{ }^{5}$ Department of Microbiology, University of Georgia, Athens, Georgia 30602, USA

15

$16{ }^{\#}$ Current address: Department of Biochemistry and Biophysics, University of California San

17 Francisco School of Medicine, San Francisco, California, 94158 USA

18 §Current address: Center for Infectious Disease Imaging (CIDI), Radiology and Imaging Sciences,

19 NIH Clinical Center, National Institutes of Health (NIH), Bethesda, Maryland 20892, USA

20

$21{ }^{*}$ Correspondence to: mswidergall@lundquist.org; sfiller@ucla.edu 


\section{Abstract}

During oropharyngeal candidiasis (OPC), Candida albicans invades and damages oral epithelial cells, which respond by producing proinflammatory mediators that recruit phagocytes to foci of infection. The ephrin type-A receptor 2 (EphA2) detects $\beta$-glucan and plays a central role in stimulating epithelial cells to release proinflammatory mediators during OPC. The epidermal growth factor receptor (EGFR) also interacts with $C$. albicans and is known to be activated by the Als3 adhesin/invasin and the Ece1/Candidalysin pore-forming toxin. Here, we investigated the interactions among EphA2, EGFR, Als3 and Ece1/Candidalysin during OPC. We found that Als3 and Ece1/Candidalysin function in the same pathway to damage epithelial cells in vitro. They also work together to cause OPC in mice. EGFR and EphA2 constitutively associate with each other as part of a physical complex and are mutually dependent for $C$. albicans-induced activation. In vitro, either Als3 or Ece1/Candidalysin is required for C. albicans to activate EGFR, sustain EphA2 activation, and stimulate epithelial cells to secrete CXCL8/IL-8 and CCL20. In the mouse model of OPC, Ece1/Candidalysin alone activates EGFR and induces CXCL1/KC and CCL20

37 production. Ece1/Candidalysin is also necessary for the production of IL-1a and IL-17A independently of Als3 and EGFR. These results delineate the complex interplay between host cell receptors and $C$. albicans virulence factors during the induction of OPC and the resulting oral inflammatory response. 


\section{Author summary}

43 Oropharyngeal candidiasis occurs when the fungus Candida albicans proliferates in the mouth.

44 The disease is characterized by fungal invasion of the superficial epithelium and a localized

45 inflammatory response. Two $C$. albicans virulence factors contribute to the pathogenesis of

46 OPC, Als3 which enables the organisms to adhere to and invade host cells and

47 Ece1/Candidalysin which is pore-forming toxin that damages host cells. Two epithelial cell

48 receptors, ephrin type-A receptor 2 (EphA2) and the epidermal growth factor receptor (EGFR)

49 are activated by $C$. albicans. Here, we show that EphA2 and EGFR form part of complex and

50 that each receptor is required to activate the other. Als3 and Ece1/Candidalysin function in the

51 same pathway to damage epithelial cells. In isolated epithelial cells, both of these virulence

52 factors activate EphA2 and EGFR, and stimulate the production of inflammatory mediators. In

53 the mouse model of OPC, Ece1/Candidalysin elicits of a subset of the oral inflammatory

54 response. Of the cytokines and chemokines induced by this toxin, some require the activation of

55 EGFR while others are induced independently of EGFR. This work provides a deeper

56 understanding of the interactions among $C$. albicans virulence factors and host cell receptors

57 during OPC. 
bioRxiv preprint doi: https://doi.org/10.1101/491076; this version posted May 7, 2020. The copyright holder for this preprint (which was not certified by peer review) is the author/funder, who has granted bioRxiv a license to display the preprint in perpetuity. It is made available under aCC-BY 4.0 International license.

58

59 Keywords: Candida albicans, oropharyngeal candidiasis, epithelial cell, receptor, inflammatory

60 response, endocytosis, invasin, Candidalysin 


\section{Introduction}

Oropharyngeal candidiasis is characterized by superficial fungal invasion of the oral mucosa, epithelial cell death, and leukocyte recruitment to the focus of infection [1]. C. albicans can invade the epithelial cell lining of the oropharynx by two mechanisms, active penetration and induced endocytosis. Active penetration occurs when a progressively elongating hypha physically pushes its way into the epithelial cell [2]. Induced endocytosis occurs when invasins such as Als1, Als3 and Ssa1 expressed by a hypha interact with epithelial cell receptors such as E-cadherin, HER2, and the epidermal growth factor receptor (EGFR), stimulating the epithelial cell to endocytose the organism [3-5]. C. albicans also damages epithelial cells by secreting Ece1, which is processed by the Kex2 protease to form Candidalysin, a pore-forming toxin $[6,7]$.

The epithelial cells that line the oropharynx sense the presence of $C$. albicans and orchestrate the host inflammatory response to fungal overgrowth. In addition to producing host defense peptides that have direct antifungal activity, oral epithelial cells secrete alarmins, proinflammatory cytokines, and chemokines that recruit phagocytes to foci of infection and enhance their candidacidal activity to limit the growth of the invading fungus [8-11]. This epithelial cell response is amplified by interleukin (IL)-17, which is secreted by $ү \delta$ T cells, innate TCRaß ${ }^{+}$ cells, and type-3 innate lymphoid cells [12-15].

Recently, it has become clear that the proinflammatory response to $C$. albicans is triggered when the fungus activates specific epithelial cell receptors. We determined that the ephrin typeA receptor 2 (EphA2) is an epithelial cell receptor that senses exposed $\beta$-glucan on the fungal surface. When C. albicans proliferates, EphA2 is activated, stimulating oral epithelial cells to secrete host defense peptides and proinflammatory mediators. In mice, EphA2 activation is required for the early production of IL-17A, and Epha2 $2^{--}$mice are highly susceptible to the initial stages of OPC $[16,17]$. Although EphA2 is required for the normal host defense against OPC, exposure of oral epithelial cells to purified $\beta$-glucan in vitro induces only transient EphA2 activation 
and is not sufficient to initiate a significant inflammatory response. By contrast, exposure to live C. albicans induces sustained EphA2 activation and a strong inflammatory response [16].

Another proinflammatory epithelial cell stimulus is Candidalysin. This toxin causes an influx of calcium into the epithelial cells, which activates matrix metalloproteases and induces shedding of native EGFR ligands, leading to activation of EGFR signaling and a proinflammatory response by epithelial cells [18].

In the current study, we sought to elucidate how C. albicans infection prolongs EphA2 activation and induces a proinflammatory response during OPC. We found that in vitro Als3 and Ece1 function in the same pathway to activate epithelial cell EGFR, which maintains EphA2 phosphorylation and stimulates the secretion of CXCL8/IL-8 and CCL20. In mice with acute OPC, pharmacological inhibition of EGFR leads to a reduction in oral fungal burden and impaired inflammatory response during disease progression. Maximal mucosal infection requires Als 1 and Als3, which act in the same pathway as Ece1, while the mucosal inflammatory response is largely driven by Ece1. Thus, C. albicans activation of EGFR mediates both fungal invasion of the epithelium and induction of the local inflammatory responses to this fungus.

\section{Results}

\section{The cellular fate of epithelial EphA2 differs depending on the type of stimulation}

When oral epithelial cells are infected with yeast-phase $C$. albicans, the fungus germinates and begins to form hyphae within $60 \mathrm{~min}$. Previously, we found that $C$. albicans infection induces EphA2 autophosphorylation on serine 897 within 15 min of infection and that this phosphorylation is sustained for at least 90 min. By contrast, when oral epithelial cells are exposed to purified $\beta$ glucan in the form of zymosan or laminarin, EphA2 is phosphorylated for only the first 30 min of contact. At later time points, EphA2 phosphorylation returns to basal levels, even though $\beta$-glucan

110 is still present [16]. To investigate how oral epithelial cells respond to prolonged exposure to 111 different EphA2 agonists, we compared their response to the native EphA2 ligand, ephrin A1 
112 (EFNA1) and to C. albicans. After $15 \mathrm{~min}$ of exposure, both stimuli induced phosphorylation of

113 EphA2 (Fig 1A, S1A Fig). After 60 min of exposure, the two stimuli induced distinctly different

114 responses. In cells exposed to EFNA1, there was minimal phosphorylation of EphA2, and total

115 EphA2 levels declined (Fig 1B, S1B and S1C Fig). In cells exposed to C. albicans, EphA2

116 phosphorylation was sustained and there was no decrease in total EphA2 levels. Thus, exposure

117 to C. albicans not only induces EphA2 phosphorylation, but prevents the subsequent EphA2

118 degradation that normally occurs with prolonged exposure to EFNA1 [19].

\section{EGFR activation sustains $C$. albicans-induced EphA2 phosphorylation}

121 EphA2 and EGFR function in the same pathway to mediate the endocytosis of $C$. albicans by oral epithelial cells in vitro. Also, EphA2 is required for $C$. albicans to activate EGFR because siRNA knockdown of EphA2 in oral epithelial cells blocks fungal-induced phosphorylation of EGFR [16]. Cross-talk between EphA2 and EGFR has also been observed in other cell types [20, 21]. To determine if EGFR is required for sustained activation of EphA2, we tested the effects of inhibiting EGFR on C. albicans-induced EphA2 phosphorylation. When EGFR was either knocked down with siRNA or inhibited with the specific EGFR kinase inhibitor, gefitinib [22], EphA2 phosphorylation was transient, occurring within 30 min of infection, but declining to basal levels by 90 min (Fig 1C-1E, S1D-S1F Fig). Therefore, activation of EGFR by $C$. albicans is required to sustain EphA2 phosphorylation.

Cross talk between EphA2 and EGFR may reflect a physical interaction between these

132 two receptors. We investigated this possibility by immunoprecipitation experiments. When EphA2 133 was immunoprecipitated from lysates of uninfected epithelial cells, EGFR was pulled down with it 134 (Fig 1F and 1G). The interaction between EphA2 and EGFR appeared to be constitutive because 135 the amount of EGFR that was associated with EphA2 did not change significantly when the 136 epithelial cells were infected with $C$. albicans. In reciprocal experiments, we determined that 137 immunoprecipitation of EGFR from infected and uninfected epithelial cells also pulled down 
similar amounts of EphA2 (Fig $1 \mathrm{~F}$ and $1 \mathrm{G}$ ). These results indicate that EphA2 and EGFR likely form part of a complex that enables each receptor to influence the activity of the other.

\section{C. albicans Als3 and Ece1 are required for prolonged EphA2 activation}

Two C. albicans virulence factors, the Als3 invasin and the Ece1/Candidalysin toxin, have been shown to be required for activation of EGFR $[18,23,24]$. To investigate the relationship between Als3 and Ece1/Candidalysin and the stimulation of epithelial cells, we constructed als $3 \Delta / \Delta$ and ece $1 \Delta / \Delta$ single gene deletion mutants and an $a / s 3 \Delta / \Delta$ ece $1 \Delta / \Delta$ double gene deletion mutant. As expected $[3,7]$, when epithelial cells were infected with either the als3 $\Delta / \Delta$ or als $3 \Delta / \Delta$ ece $1 \Delta / \Delta$ mutants, the number of cell-associated C. albicans cells (a measure of adherence) and endocytosed C. albicans cells was significantly reduced relative to the wild-type strain (Fig 2A). By contrast, the ece1 $1 \Delta / \Delta$ mutant acted similarly to the wild-type parent strain in these assays. Also, both the als3 $\Delta / \Delta$ and ece $1 \Delta / \Delta$ mutants caused significantly less epithelial cell damage than the wild-type strain (Fig 2B). The als3 $\Delta / \Delta$ ece $1 \Delta / \Delta$ double mutant caused the least amount of epithelial cell damage, which was significantly less than that caused by the als $3 \Delta / \Delta$ single mutant (Fig 2B). Collectively, these data support the model that Als3-mediated epithelial cell invasion is required for Ece1-induced damage.

To determine if Als3 and Ece1 are required for sustained EphA2 activation, we analyzed the phosphorylation of EphA2 and EGFR in response to the als $3 \Delta / \Delta$ and ece $1 \Delta / \Delta$ mutant strains. While infection with both mutant strains induced EphA2 phosphorylation in oral epithelial cells after $30 \mathrm{~min}$, neither mutant strain was able to sustain EphA2 phosphorylation at $90 \mathrm{~min}$ (Fig 2C, S2 Fig). This lack of sustained EphA2 phosphorylation was likely due to the absence of EGFR activation, because neither the als3 $\Delta / \Delta$ nor the ece1 $\Delta / \Delta$ mutant induced significant phosphorylation of EGFR. 
To investigate the roles of EGFR and EphA2 in stimulating an epithelial cell proinflammatory response in vitro, we used siRNA to knock down EGFR and EphA2 prior to infecting the cells with C. albicans. We found that knockdown of EGFR inhibited the secretion of CXCL8/IL-8 and CCL20 similarly to knockdown of EphA2 (Fig 3A). Although knockdown of EGFR had no effect on the

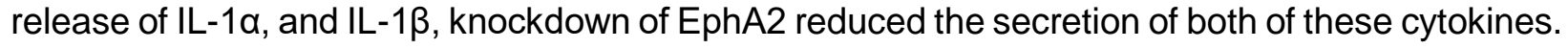
Inhibition of EGFR phosphorylation with gefitinib also inhibited the secretion of CXCL8/IL-8 and

171 CCL20, but not IL-1 $\alpha$ or IL-1 $\beta$ (Fig 3B). These results suggest that activation of both EphA2 and 172 EGFR is required for $C$. albicans to induce epithelial cells to secrete CXCL8/IL-8 and CCL20. 173 They also indicate that EphA2 mediates production of IL-1 $\alpha$ and IL-1 $\beta$ independently of EGFR. Next, we investigated the roles of Als3 and Ece1 in stimulating oral epithelial cells in vitro. Infection with the als $3 \Delta / \Delta$ and ece1 $\Delta / \Delta$ single mutants and the als $3 \Delta / \Delta$ ece $1 \Delta / \Delta$ double mutant induced significantly less secretion of CXCL8/IL-8, CCL20, IL-1 $\alpha$, and IL-1 $\beta$ than the wild-type parent strain (Fig 3C). Of note, the epithelial cell stimulation defect of the als $3 \Delta / \Delta$ ece $1 \Delta / \Delta$ double pathway to activate EGFR, which prolongs EphA2 phosphorylation and stimulates oral epithelial cells to secrete CXCL8/IL-8 and CCL20. These results also suggest that Als3 and Ece1/Candidalysin induce the production of IL-1 $\alpha$ and IL-1 $\beta$ via a mechanism that requires EphA2 but is independent of EGFR.

\section{TR146 epithelial cells}

187 The above experiments were conducted with OKF6/TERT-2 oral epithelial cells, which were 188 generated by transfecting normal human cells with a constitutively active telomerase [25]. Using 
the TR146 human buccal squamous cell carcinoma cell line, Ho et al. also found that $C$. albicansinduced activation of EGFR is required for the fungus to stimulate oral epithelial cells to secrete multiple cytokines [18]. One difference between their results and those presented here is that EGFR was required for induction of IL-1 $\alpha$ and IL-1 $\beta$ in TR146 cells but not OKF6/TERT-2 cells. To investigate this difference, we compared the interactions of $C$. albicans with both cell lines. We

194 found that while the adherence of $C$. albicans to both types of epithelial cells was similar, TR146 195 cells endocytosed over 3-fold more $C$. albicans cells than did OKF6/TERT-2 cells (Fig 4A). Also, 196 gefitinib modestly inhibited the adherence of $C$. albicans to TR146 cells, but not OKF6/TERT-2 cells, and it inhibited C. albicans endocytosis by TR146 cells by $30 \%$ and endocytosis by OKF6/TERT-2 cells by $64 \%$. Thus, in TR146 cells relative to OKF6/TERT-2 cells, EGFR is more important for adherence but less important for inducing the endocytosis of $C$. albicans.

We also used a ${ }^{51} \mathrm{Cr}$ release assay to compare the susceptibility of the two cell types to damage induced by $C$. albicans. In a time-course study, $C$. albicans caused significantly more damage to TR146 cells than to OKF6/TERT-2 cells at all time points (Fig 4C). In fact, after $24 \mathrm{hr}$ of infection, C. albicans-induced damage of TR146 cells was near-maximal, whereas the extent of damage to the OKF6/TERT-2 cells was significantly less (Fig 4D). Gefitinib had no effect on the extent of $C$. albicans-induced damage to either cell line. Collectively, these data indicate that TR146 cells are more susceptible to $C$. albicans-induced damage than OKF6/TERT-2 cells.

The extent of EGFR phosphorylation and cytokine production by TR146 cells and OKF6/TERT-2 cells also differed. Uninfected TR146 cells had significantly higher levels of total and phosphorylated EGFR than OKF6/TERT-2 cells (Fig 4E, S3 Fig). Uninfected TR146 cells 210 also secreted over 30-fold more CXCL8/IL-8, 15-fold more CCL20, and 2-fold more IL-1 $\alpha$ than 211 OKF6/TERT-2 cells (Fig 4F). The levels of these cytokines and IL-1 $\beta$ significantly increased when 212 the TR146 cells were infected with $C$. albicans (Fig 4G). While gefitinib inhibited the production of 213 CXCL8/IL-8 and CCL20 by $C$. albicans infected TR146 cells, it also decreased the production of 
IL-1 $\alpha$ and IL-1 $($ Fig 4G). Thus, EGFR governs $C$. albicans-induced production of chemokines in both cell lines, but it regulates production of IL-1 $\alpha$ and IL-1 $\beta$ only in TR146 cells.

\section{Inhibition of EGFR decreases EphA2 phosphorylation, oral fungal burden, and the host} inflammatory response during OPC

To assess the role of EGFR in mediating the host inflammatory response to $C$. albicans during OPC, we treated immunocompetent mice with gefitinib and then orally inoculated them with C. albicans. Immunocompetent mice were used to avoid potentially confounding effects of immunosuppression on the host inflammatory response. When immunocompetent mice are orally inoculated with C. albicans strain SC5314, infection persists for 2 days, after which the organism is cleared by the host inflammatory response $[14,26]$.

Using flow cytometry and phosphospecific antibodies, we assessed the effects of gefitinib on EGFR and EphA2 phosphorylation in the oral epithelium. As predicted by the in vitro data, treatment with gefitinib reduced the phosphorylation of both EGFR and EphA2 in CD45- EpCam+ cells after $1 \mathrm{~d}$ of infection (Fig 5). At this time point, the gefitinib-treated mice had a 3-fold reduction in oral fungal burden compared to untreated mice (Fig 6A), probably due to inhibition of epithelial cell invasion by the drug.

To determine the effects of gefitinib on the inflammatory response, we measured whole tongue levels of CXCL1/KC, CCL20, IL-1 $\alpha$ and IL-1 $\beta$. To obtain a more comprehensive view of the effects of gefitinib, we also measured the levels of IL-17A, S100A8, and TNFa. After 1 day of infection, the oral tissues of the gefitinib-treated mice contained significantly less CXCL1/KC, CCL20, IL-1a, IL-1ß, IL-17A, and the host defense peptide S100A8 than control mice (Fig 6B). There were also significantly fewer neutrophils and inflammatory monocytes in the oral tissues of the gefitinib-treated mice (Fig 6C and 6D, S4 Fig). After 2 days of infection, the gefitinib-treated and control mice had similar oral fungal burden (Fig 6A). At this time point, treatment with gefitinib

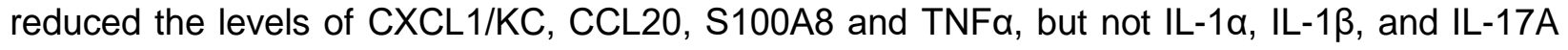


240

241

242

243

244

245

246

247

248

249

250

251

252

253

254

255

256

257

258

259

260

261

262

(Fig 6E). These results indicate that blocking EGFR reduces a subset of the early inflammatory response to acute OPC in immunocompetent mice.

Because gefitinib impaired the host inflammatory response to $C$. albicans, we investigated its effects on the candidacidal activity of neutrophils and macrophages. We found that gefitinib did not decrease the capacity of human neutrophils, bone marrow (BM) neutrophils isolated from gefitinib-treated mice, or murine BM derived macrophages to kill $C$. albicans in vitro (S5 Fig). Taken together, these results indicate that while EGFR signaling is required for epithelial cells to mount a pro-inflammatory response to $C$. albicans, it is dispensable for governing phagocyte killing of the organism.

\section{C. albicans adhesins/invasins and Ece1/Candidalysin function together during OPC}

To investigate the roles Als3 and Ece1/Candidalysin in stimulating the host response during oropharyngeal candidiasis, we orally infected immunocompetent mice with $C$. albicans als $3 \Delta / \Delta$ and ece $1 \Delta / \Delta$ mutants. After 1 day of infection, mice inoculated with the als $3 \Delta / \Delta$ mutant had reduced oral fungal burden relative to those infected with the wild-type strain, and mice inoculated with the ece $1 \Delta / \Delta$ mutant had an even greater decrease in fungal burden (Fig $7 \mathrm{~A})$. After 2 days of infection, the fungal burden of mice infected with the als $3 \Delta / \Delta$ mutant was similar to that of mice infected with the wild-type strain, whereas the fungal burden of mice infected with the ece1 $\Delta / \Delta$ mutant remained significantly lower (Fig 7A). We also determined that C57BL/6 mice infected with the ece $1 \Delta / \Delta$ mutant constructed in either strain SC5314 or BWP17 had reduced oral fungal burden (S6 Fig). Thus, in the acute oropharyngeal candidiasis model, Als3 is necessary for maximal infection at day 1, whereas Ece1/Candidalysin is required for maximal infection at both days 1 and 2 .

C. albicans must first adhere to host cells in order to invade them. C. albicans Als1 is structurally similar to Als3 and it can function as both an adhesin and invasin $[3,27]$. We reasoned that the presence of Als 1 in als $3 \Delta / \Delta$ mutant could enable the organism to adhere to and invade 
the oral epithelium in the absence of Als3. To test this hypothesis, we constructed als $1 \Delta / \Delta$, als $1 \Delta / \Delta$ als $3 \Delta / \Delta$, and als $1 \Delta / \Delta$ als $3 \Delta / \Delta$ ece $1 \Delta / \Delta$ mutants. In vitro, the als $1 \Delta / \Delta$ als $3 \Delta / \Delta$ mutant had significantly reduced adherence to OKFG/TERT-2 cells compared to the als $3 \Delta / \Delta$ mutant, indicating that Als1 and Als3 make independent contributions to C. albicans adherence (S7A Fig). Because the als $3 \Delta / \Delta$ single mutant was endocytosed so poorly by oral epithelial cells and caused so little host cell damage, deletion of $A L S 1$ did not reduce these interactions further (S8B and 272 S8C Fig)

After 1 day of oral infection, mice infected with the als $1 \Delta / \Delta$ als $3 \Delta / \Delta$ mutant had a slight reduction in oral fungal burden relative to mice infected with the wild-type strain, but this difference was not statistically significant (Fig 7B). At this time point, the fungal burden of mice infected with ece $1 \Delta / \Delta$ single mutant and the als $1 \Delta / \Delta$ als $3 \Delta / \Delta$ ece $1 \Delta / \Delta$ triple mutant was significantly reduced. After 2 days of infection, the fungal burden of mice infected with the als $1 \Delta / \Delta$ als $3 \Delta / \Delta$ double mutant was decreased to the same extent as mice infected with either the ece $1 \Delta / \Delta$ single mutant or the als $1 \Delta / \Delta$ als $3 \Delta / \Delta$ ece $1 \Delta / \Delta$ triple mutant (Fig $8 \mathrm{~B}$ ). These data suggest that adherence and invasion mediated by Als1 and Als3 combined with host cell damage caused by Ece1/Candidalysin play key roles in inducing acute OPC.

To determine the contributions of Als1, Als3 and Ece1/Candidalysin to the induction and maintenance of the oral innate immune response, we determined the levels of inflammatory mediators in the infected tongues after 1 and 2 days of infection. Three different patterns of response were observed. The levels of IL-1 $\beta$ were similar in mice infected with all strains of $C$. albicans, indicating that the production of this cytokine is independent of Als1, Als3 and 287 Ece1/Candidalysin (Fig 8). The levels of many inflammatory mediators, such as IL-1a, CXCL1/KC 288 CCL20, IL-17A, and S100A8 were decreased to the same extent in mice infected with either the $289 \operatorname{ece} 1 \Delta / \Delta$ mutant or the als $1 \Delta / \Delta$ als $3 \Delta / \Delta$ ece $1 \Delta / \Delta$ mutant, suggesting that the production of these 290 mediators is dependent on Ece1/Candidalysin but independent of Als1 and Als3. The levels of 291 TNFa were significantly reduced only in mice infected with the als $1 \Delta / \Delta$ als $3 \Delta / \Delta$ ece $1 \Delta / \Delta$ mutant, 
signifying that Als1, Als3, and Ece1/Candidalysin function cooperatively to induce the production of this cytokine. Thus, while the production of some inflammatory mediators during OPC is largely driven by Ece1/Candidalysin, Als1 and Als3 contribute to the production of TNFa.

\section{Discussion}

Oral epithelial cells play a central role in orchestrating the host defense against $C$. albicans during OPC $[1,11,28,29]$. Our current data show that in oral epithelial cells, EphA2 and EGFR form part of a complex and that EGFR activation mediates a subset of proinflammatory response to this fungus. Previously, we found that EphA2 activation is required for $C$. albicans to stimulate EGFR [16]. Here, we determined that activation of EGFR is in turn necessary for $C$. albicans to sustain activation of EphA2, both in vitro and in vivo. Thus, these two receptors function interdependently to mediate the epithelial cell response to $C$. albicans. These data also indicate that the initiation of a proinflammatory response in oral epithelial cells requires two signals, one induced by EphA2 binding to fungal $\beta$-glucans and the other induced by EGFR stimulated by fungal invasins and Ece1/Candidalysin.

EphA2 and EGFR are known to interact in epithelial cell cancers, especially those that have become resistant to EGFR inhibitors, in which siRNA knockdown of EphA2 restores sensitivity to pharmacological EGFR inhibition [30, 31]. Interestingly, treatment of malignant cell lines with soluble EFNA1 has the same effect as EphA2 siRNA, presumably because EFNA1 311 induces EphA2 endocytosis and subsequent degradation. Our data indicate that C. albicans 312 activates EphA2 differently than EFNA1 because binding of $C$. albicans stabilizes EphA2 and 313 prevents its degradation. The sustained EphA2 protein levels likely contribute to the prolonged 314 EphA2 signaling induced by $C$. albicans infection.

We found that $C$. albicans activation of EGFR resulted in the production of 316 proinflammatory mediators by two different oral epithelial cell lines. Recently, it has been reported 317 that Ece1/Candidalysin activates EGFR and stimulates the TR146 oral epithelial cell line to 



with siRNA or inhibition of EGFR with gefitinib significantly reduced C. albicans-induced production of CXCL8/IL-8 and CCL20 by both TR146 cells and OKF6-TERT2 cells. However, inhibition of EGFR only decreased production of II- $1 \alpha$ and IL-1 $\beta$ by TR146 cells, but not by OKF6TERT2 cells. It was also determined that TR146 cells had higher basal levels of total and phosphorylated EGFR than OKF6-TERT2 cells, which may explain why cytokine production by TR146 cells was more sensitive to EGFR inhibition. Nevertheless, the result with both oral epithelial cells lines indicate that $C$. albicans activates EGFR, which induces the production of proinflammatory mediators.

The current data indicate a functional interaction between Als3 and Ece1/Candidalysin. Consistent with previous reports [3,7], we found that both the als $3 \Delta / \Delta$ mutant and the ece $1 \Delta / \Delta$ mutant were defective in damaging oral epithelial cells in vitro. Also, these two mutants were similarly impaired in their capacity to stimulate epithelial cells to secrete proinflammatory mediators. Strikingly, deletion of $A L S 3$ in the ece $1 \Delta / \Delta$ mutant did not lead to a further reduction in epithelial cell damage and production of proinflammatory mediators. These results indicate that Als3 and Ece1/Candidalysin function in the same pathway to damage epithelial cells and stimulate them to secrete proinflammatory mediators in vitro. A potential explanation for the functional linkage between Als3 and Ece1/Candidalysin is that when C. albicans hyphae are endocytosed via Als3, secreted Ece1/Candidalysin is contained within the endocytic vacuole, where it accumulates to sufficiently high concentration that it damages the epithelial cell and activates EGFR to induce the production of inflammatory mediators. This possibility is supported by our previous finding that inhibiting the endocytosis of $C$. albicans by treating epithelial cells with cytochalasin $\mathrm{D}$ also blocks fungal-induced damage [32].

The central role of EGFR in mediating the host inflammatory response was demonstrated in the immunocompetent mouse model of OPC. Treatment of mice with gefitinib inhibited $C$. albicans-induced phosphorylation of both EphA2 and EGFR in the oral epithelial cells, and 
reduced the tissue levels of CXCL1/KC, CCL20, S100A8 after both 1 and 2 days of infection. As a result, the accumulation of neutrophils and inflammatory monocytes in the oral tissues was

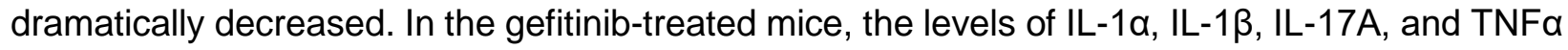
were only reduced at a single time point, suggesting that the production of these cytokines may be governed independently of EGFR.

Inhibition of EGFR has different effects in different models of mucosal infection. Recently, Ho et al. [18] reported that in the zebrafish swimbladder model of mucosal candidiasis, gefitinib treatment impaired the accumulation of neutrophils and led to enhanced mortality, even though it had no effect on fungal burden. Our findings demonstrate that in immunocompetent mice, gefitinib has different effects; although it reduces cytokine production and accumulation of phagocytes, it also decreases oral fungal burden. We and others have found previously that EGFR inhibition also reduces oral fungal burden in steroid-immunosuppressed mice [5, 18]. As inhibition of EGFR reduces $C$. albicans endocytosis by oral epithelial cells in vitro, it is probable that the decrease in oral fungal burden by EGFR inhibition is due to impaired epithelial cell invasion in vivo.

When we tested the virulence of the C. albicans mutants with deletions in ALS1, ALS3, and/or ECE1, we found that some of the in vitro data were recapitulated in mice. After 2 days of infection, mice inoculated with the ece $1 \Delta / \Delta$ mutant, the als $1 \Delta / \Delta$ als $3 \Delta / \Delta$ mutant, and the als $1 \Delta / \Delta$ als3 $\Delta / \Delta$ ece $1 \Delta / \Delta$ mutant all had a similar reduction in oral fungal burden. This finding parallels the reduced epithelial cell damage induced by these strains in vitro and indicates that the combination of Als1 and Als3 function along with Ece1/Candidalysin to induce oral infection. It was notable that although the als $1 \Delta / \Delta$ als $3 \Delta / \Delta$ mutant had extremely impaired adherence to and invasion of oral epithelial cells In vitro, its virulence defect in mice was less severe. A likely explanation for this result is that other adhesins and invasins such as Hwp1 [33] and Ssa1 [4] may compensate for the absence of Als 1 and Als3 in vivo. It is also possible that the als $1 \Delta / \Delta$ als3 $\Delta / \Delta$ mutant may invade oral epithelial cells in vivo by a receptor-independent mechanism, such as by active penetration [2]. 
The mouse data indicated that different subsets of the host inflammatory response are

371 induced by different combinations of Als1, Als3, and Ece1/Candidalysin. Mice infected with the

372 ece $1 \Delta / \Delta$ mutant had reduced levels of $C X C L 1 / K C$ and $C C L 20$ in their oral tissues, similar to mice

373 that had been treated with gefitinib. Although mice infected with the als $1 \Delta / \Delta$ als $3 \Delta / \Delta$ ece $1 \Delta / \Delta$

374 mutant had a comparable reduction in these chemokines, animals infected with the als $1 \Delta / \Delta$

$375 \mathrm{als} 3 \Delta / \Delta$ had wild-type levels. Collectively, these results suggest that Ece1/Candidalysin is

376 necessary for $C$. albicans to active EGFR in vivo, which stimulates the production of CXCL1/KC

377 and CCL20. These results also indicate that in vivo, Als1 and Als3 are dispensable for the

378 induction of this aspect of the inflammatory response.

The data with the mutant strains of

C. albicans showed that Als1, Als3, and

Ece1/Candidalysin stimulate some proinflammatory responses independently of EGFR. While

mice treated with gefitinib only had reduced levels of IL-1 $\alpha$ and IL-17A at day 1 post infection,

mice infected with either the ece $1 \Delta / \Delta$ mutant or the als $1 \Delta / \Delta$ als $3 \Delta / \Delta$ ece $1 \Delta / \Delta$ mutant had reduced

TNFa production is independent of EGFR signaling, but dependent on the combined activity of Als1, Als3, and Ece1/Candidalysin.

The current results indicate that the capacity of Ece1/Candidalysin to induce IL-1 $\beta$ production is dependent on the anatomic site of infection. We found that mice infected with the ece $1 \Delta / \Delta$ mutant strains had wild-type levels of IL-1 $1 \beta$ in their oral tissues, indicating that production

392 of this cytokine is independent of Ece1/Candidalysin. In the mouse model of disseminated 393 candidiasis, Ece1/Candidalysin is dispensable for IL-1 $\beta$ production in the kidneys [34], but 394 essential for IL-1 $\beta$ production in the brains [35]. Thus, $C$. albicans infection induces IL-1 $\beta$ 395 production in the oral mucosa by a different mechanism than in the brain. 
A paradoxical finding was that although mice infected with the ece $1 \Delta / \Delta$ mutant had a markedly reduced inflammatory response, they also had reduced oral fungal burden. This reduction in oral fungal burden was observed in two strains of mice infected with independent ece $1 \Delta / \Delta$ mutants and has also been reported in the immunosuppressed mouse model of OPC

400 [7]. Because of the decreased inflammatory response induced by the ece $1 \Delta / \Delta$ mutant, it would 401 have been expected that this strain would be able to proliferate unimpeded in the oral cavity. For 402 example, when mice are infected intravenously with an ece1 $\Delta / \Delta$ mutant, there is significantly 403 reduced production of proinflammatory cytokines and accumulation of neutrophils in the brain, 404 and this dampened inflammatory response leads to increased brain fungal burden [35]. One 405 potential explanation for the reduced oral fungal burden in mice infected with the ece $1 \Delta / \Delta$ mutant 406 is that even in the absence of Ece1/Candidalysin, there is still some inflammatory response, 407 possibly induced by IL-1 [36] and the residual phagocytes are able to clear the fungus. Alternatively, epithelial cell damage by Ece1/Candidalysin may release nutrients that are vital for fungal proliferation.

411 for $C$. albicans-induced activation and that the fungal adhesins/invasins Als1 and Als3 function 412 together with Ece1/Candidalysin to cause epithelial cell damage and induce OPC. Although either Als3 or Ece1/Candidalysin is required for $C$. albicans to activate EGFR and stimulate epithelial 414 cells to secrete proinflammatory mediators in vitro, induction of much of the oral inflammatory 415 response requires Ece1/Candidalysin-induced activation of EGFR in vivo. However, some 416 inflammatory responses are induced independently of both Ece1/Candidalysin-and EGFR. 417 Studies to delineate these additional fungal factors and signaling pathways are currently 418 underway. 


\section{Materials and Methods}

\section{Ethics statement}

423 All animal work was approved by the Institutional Animal Care and Use Committee (IACUC) of

424 the Lundquist Institute at Harbor-UCLA Medical Center. The collection of blood from human

425 volunteers for neutrophil isolation was also approved by the Institutional Review Board of the

426 Lundquist Institute at Harbor-UCLA Medical Center. Informed consent was obtained from all

427 subjects prior to phlebotomy.

\section{Fungal strains}

429 The $C$. albicans strains used in this study are listed in S1 table. For strain construction, a transient CRISPR-Cas9 system was employed [37]. Primers used for strain construction and confirmation are listed in S2 table. To construct the initial ece1 $\Delta / \Delta$ and als3 $\Delta / \Delta$ mutants, MH216, a his $1 \Delta / \Delta$

432 NatR derivative of strain SC5314 was utilized [38]. To delete ECE1, MH216 was transformed with 433 the Cas9 DNA cassette, ECE1-2 sgRNA DNA cassette, NAT1-5 sgRNA DNA cassette, and ece1A::r1HIS1r1 repair template. ALS3 was deleted in a similar manner, except that the ALS35P sgRNA DNA cassette and als3A::r1HIS1r1 repair template were used. Transformants were selected on complete synthetic medium (CSM) plates without histidine, and screened for nourseothricin sensitivity on YPD + nourseothricin plates. His+ NatS transformants were checked

438 for deletion of ECE1 or ALS3 by PCR genotyping using primers ECE1 check up/F and ECE1 439 check int/R, and primers ALS3 chk up/F and ALS3 chk int/R, respectively. The presence of the $440 \quad$ r1HIS1r1 cassette was verified by PCR genotyping using primers ECE1 check up/F and CdHIS1 441 Check Int/R or primers ALS3 chk up/F T and CdHIS1 Check Int/R. To generate the als3 $\Delta / \Delta$ 442 ece $1 \Delta / \Delta$ double mutant, the als3 $\Delta / \Delta$ mutant MH562 was independently transformed with the 443 Cas9 DNA cassette, the ECE1-2 sgRNA DNA cassette, and the ece1A::r3NAT1r3 repair 444 template. Transformants were selected on YPD plates containing $400 \mu \mathrm{g} / \mathrm{ml}$ nourseothricin and 445 NatR transformants were PCR genotyped to verify deletion of ECE1 as described above. 
The second set of $C$. albicans mutants was constructed in strain SC5314 using the

447 transient CRISPR-Cas9 system [37] combined with the Nat flipper approach [39, 40]. Briefly, the

448 gRNA and Cas9 constructs were amplified from vector pV1093 (S3 Table) by PCR [41]. The gene

449 deletion constructs with the maltose promoter-driven flippase and actin promoter-driven clonNAT

450 selective marker were amplified with primers carrying micro-arms that were homologous to the

451 flanking regions of target genes from a vector derived from pSF2A-mScarlet [39]. The gRNA,

452 Cas9, and repair constructs were mixed and transformed into $C$. albicans cells using the lithium

453 acetate heat-shock method [42]. Transformants were selected by growth on yeast extract peptone

454 dextrose (YPD) agar containing with $200 \mu \mathrm{g} / \mathrm{mL}$ of clonNAT. Successfully gene deletion was

455 confirmed with multiple rounds of diagnostic PCRs, including confirming the integration of the

456 deletion construct at the gene locus and the absence of the target gene, gRNA and Cas9

457 constructs. To recycle the dominant selective drug marker, confirmed transformants were cultured

458 in YPM (YPD in which glucose was replaced with $2 \%$ maltose) broth for 2 days in a $30^{\circ} \mathrm{C}$ shaking

459 incubator. 200-500 cells were then plated onto YPM plates. Individual colonies from YPM plates

460 were then replicate plated onto YPM+clonNAT. NatS colonies were then picked and analyzed by

461 PCR. Chromosomal rearrangement of constructed mutant strains was excluded by diagnostic

462 PCR.

$463 \quad$ For the experiments, the $C$. albicans cells were grown for $18 \mathrm{~h}$ in YPD broth in a shaking

464 incubator at $30^{\circ} \mathrm{C}$. The fungal cells were harvested by centrifugation, washed twice with

465 phosphate-buffered saline (PBS), and counted using a hemacytometer.

466 Oral epithelial cells

467 The OKF6/TERT-2 immortalized human oral epithelial cell line was kindly provided by J.

468 Rheinwald (Harvard University, Cambridge, MA) [25] and was cultured as previously described

469 [24]. OKF6/TERT-2 cells were authenticated by RNA-Seq [43] and tested for mycoplasma

470 contamination. The TR146 buccal mucosa squamous cell carcinoma epithelial cell line was 
bioRxiv preprint doi: https://doi.org/10.1101/491076; this version posted May 7, 2020. The copyright holder for this preprint (which was not certified by peer review) is the author/funder, who has granted bioRxiv a license to display the preprint in perpetuity. It is made available under aCC-BY 4.0 International license.

471 generously provided by J. R. Naglik (Kings College London, UK) and was cultured as previously

472 described [18].

473 


\section{$474 \quad$ Inhibitor and agonists}

475 The EGFR kinase inhibitor gefitinib (Selleckchem) was dissolved in DMSO and used at a final

476 concentration of $1 \mu \mathrm{m}$. It was added to the host cells 60 min prior to infection and remained in the

477 medium for the entire incubation period. Control cells were incubated with a similar concentration

478 of DMSO at a final concentration of $0.1 \%$. EFNA1-Fc (Acro Biosystems) was used at a final

479 concentration of $1 \mu \mathrm{g} / \mathrm{ml}$.

480 SIRNA

481 To knockdown EGFR and EphA2, OKF6/TERT-2 cells were transfected with siRNA as described 482 previously [24]. Briefly, the cells were grown in 6-well tissue culture plates and transfected with 48380 pmol EGFR siRNA (sc-29301, Santa Cruz Biotechnology), and EphA2 siRNA (sc-29304, 484 Santa Cruz Biotechnology), or a similar amount of random control siRNA (sc-37007, Santa Cruz 485 Biotechnology) using Lipofectamine 2000 (Thermo Fisher Scientific) following the manufacturer's instructions. The extent of protein knockdown was verified $72 \mathrm{~h}$ later by immunoblotting with specific antibodies. Knockdown of the protein of interest was $>80 \%$ (S1 Fig)

\section{Immunoblotting}

489 OKF6/TERT-2 cells or TR146 cells in 24-well tissue culture plates were switched to supplement free KSF medium or DMEM/F12 medium, respectively for $1 \mathrm{~h}$ and then infected with $1 \times 10^{6} \mathrm{C}$. albicans yeast for various times as described previously [16]. Next, the cells were rinsed with cold HBSS containing protease and phosphatase inhibitors, detached from the plate with a cell scraper, and collected by centrifugation. After boiling the cells in sample buffer, the resultant

494 lysate was separated by SDS-PAGE, and phosphorylation was detected by immunoblotting with 495 specific antibodies against pEphA2 (\#6347, Cell Signaling) and pEGFR (\#2234, Cell Signaling). 496 Next, the blot was stripped, and the total amount of each protein was detected by immunoblotting 497 with antibodies against EphA2 (D4A2, Cell Signaling), EGFR (\#4267, Cell Signaling), and $\beta$-actin 498 (\#a5441, Sigma). Each experiment was performed at least 3 times. 


\section{Immunoprecipitation}

501 OKF6/TERT-2 cells were grown in $75 \mathrm{~cm}^{2}$ flasks to confluency, switched to KSF medium without

502 supplements for $3 \mathrm{~h}$, and then infected with $1 \times 10^{8}$ C. albicans yeast. After 30 or $90 \mathrm{~min}$.

503 OKF6/TERT-2 were washed with ice-cold cold PBS (with $\mathrm{Mg}^{2+}$, and $\mathrm{Ca}^{2+}$ ), scraped from the

504 flasks, and lysed with $100 \mu$ ice-cold 5.8\% octyl $\beta$-D-glucopyranoside (0479-5g; VWR) in the

505 present of protease/phosphatase inhibitors. Whole cells lysates were precleared with $20 \mu$ l of

506 protein A/G plus (sc-2003; Santa Cruz Biotechnology) at $4^{\circ} \mathrm{C}$ for 30 minutes. The bead-protein

$507 \mathrm{mix}$ was centrifuged at $3000 \mathrm{rpm}$ for $30 \mathrm{sec}$ at $4^{\circ} \mathrm{C}$ and supernatants were collected. $2 \mu \mathrm{g}$ of anti-

508 EGFR antibody (sc-101; Santa Cruz Biotechnology) or anti-EphA2 antibody (\#6347, Cell

509 Signaling) was added to $500 \mu \mathrm{g}$ of protein and incubated on a rotator at $4^{\circ} \mathrm{C}$ for 2 hours. $25 \mu \mathrm{l}$ of

510 protein $A / G$ plus was added to each immunoprecipitation sample and incubated for an additional

511 hour at $4^{\circ} \mathrm{C}$. Samples were pelleted at $3000 \mathrm{rpm}$ for $30 \mathrm{sec}$, and washed 3 times in $500 \mu \mathrm{l}$ of ice-

512 cold $1.5 \%$ octyl $\beta$-D-glucopyranoside. Proteins were eluted with $30 \mu$ of $2 X$ SDS buffer and then

513 heated at $90^{\circ} \mathrm{C}$ for 5 minutes. Samples were centrifuged at $3000 \mathrm{rpm}$ for $30 \mathrm{sec}$ after which the

514 supernatants were collected, separated by SDS-PAGE, and analyzed as described above.

515 Measurement of epithelial cell endocytosis

516 The endocytosis of $C$. albicans by oral epithelial cells was quantified as described previously [44].

517 OKF6/TERT-2 or TR146 oral epithelial cells were grown to confluency on fibronectin-coated

518 circular glass coverslips in 24-well tissue culture plates and then infected for 120 min with

$5192 \times 10^{5}$ yeast-phase $C$. albicans cells per well, after which they were fixed, stained, and mounted

520 inverted on microscope slides. The coverslips were viewed with an epifluorescence microscope,

521 and the number of endocytosed organisms per high-power field was determined, counting at least

522100 organisms per coverslip. Each experiment was performed at least 3 times in triplicate.

523 Cytokine and chemokine measurements in vitro

524 Cytokine levels in culture supernatants were determine as previously described [16]. Briefly

525 OKF6/TERT-2 cells or TR146 cells in a 96-well plate were infected with $C$. albicans at a multiplicity 
526 of infection of 5 . After $8 \mathrm{~h}$ of infection, the medium above the cells was collected, clarified by

527 centrifugation and stored in aliquots at $-80^{\circ} \mathrm{C}$. The concentration of inflammatory cytokines and

528 chemokines in the medium was determined using the Luminex multipex assay (R\&D Systems).

\section{Epithelial cell damage}

530 The effects of gefitinib on extent of epithelial cell damage caused by C. albicans was determined 531 by our previously described ${ }^{51} \mathrm{Cr}$ release assay [24]. OKF6/TERT-2 cells and TR146 cells in a 24532 well plate were loaded with ${ }^{51} \mathrm{Cr}$ overnight. The next day, they were incubated with gefitinib or 533 diluent and then infected with $C$. albicans at a multiplicity of infection of 10 . At various time points, 534 the medium above the epithelial cells was collected and the epithelial cells were lysed with 535 RadiacWash (Biodex). The amount of ${ }^{51} \mathrm{Cr}$ released into the medium and remaining in the cells was determined with a gamma counter, and the percentage of ${ }^{51} \mathrm{Cr}$ released in the infected cells we compared to the release by uninfected epithelial cells. The experiment was performed 3 times

538 in triplicate.

\section{Mouse model of oropharyngeal candidiasis}

540 Male, 6 week old BALB/c mice were purchased from Taconics and C57BL/6J mice were

541 purchased from Jackson Laboratories. OPC was induced in mice as described previously [24,

542 45]. Starting on day -2 relative to infection, the mice were randomly assigned to receive gefitinib

543 or no treatment. Gefitinib was administered by adding the drug to the powdered chow diet at a

544 final concentration of 200 parts-per-million. For inoculation, the animals were sedated, and a swab

545 saturated with $2 \times 10^{7} \mathrm{C}$. albicans cells was placed sublingually for $75 \mathrm{~min}$. Mice were sacrificed

546 after 1 and 2 days of infection. The tongues were harvested, weighed, homogenized and

547 quantitatively cultured. The researchers were not blinded to the experimental groups because the 548 endpoints (oral fungal burden, cytokine levels, and leukocyte numbers) were an objective 549 measure of disease severity. 


\section{Cytokine and chemokine measurements in vivo}

552 To determine the whole tongue cytokine and chemokine protein concentrations, the mice were

553 orally infected with C. albicans as above. After 1 and 2 days of infection, the mice were sacrificed,

554 and their tongues were harvested, weighed and homogenized. The homogenates were cleared

555 by centrifugation and the concentration of inflammatory mediators was measured using a

556 multiplex bead array assay (R\&D Systems) as previously described [16, 46].

\section{Flow cytometry}

558 To detect phosphorylation of EphA2, and EGFR in the tongue of $C$. albicans infected mice, the mice were orally infected with $C$. albicans as above. After 1 of infection, the mice were sacrificed, and their tongues were harvested, fixed in 3\% PFA for $30 \mathrm{~min}$. After washing a single cell suspension was prepared as described above. Single cells were permeabilized with methanol for 10 min, washed and stained with anti-pEphA2 (\#6347, Cell Signaling) or anti-pEGFR (\#2234, Cell Signaling) antibodies over night at $4^{\circ} \mathrm{C}$. The next day the cells were further stained with anti-rabbit FITC Ab (Abcam, ab6717), CD326 (Ep-CAM)-PE (G8.8, Biolegend), CD45-APC (30-F11; BD Biosciences) and then analyzed with a BD FACSymphony A5 flow cytometer.

The number of phagocytes in the mouse tongues were characterized as described

567 elsewhere [47]. Briefly, mice were orally infected with C. albicans as described above. After $1 \mathrm{~d}$ 568 of infection, the animals were administered a sublethal anesthetic mix intraperitoneally. The 569 thorax was opened, and a part of the rib cage removed to gain access to the heart. The vena 570 cava was transected and the blood was flushed from the vasculature by slowly injecting $10 \mathrm{~mL}$ 571 PBS into the right ventricle. The tongue was harvested and cut into small pieces in $100 \mu \mathrm{L}$ of ice572 cold PBS. $1 \mathrm{~mL}$ digestion mix $(4.8 \mathrm{mg} / \mathrm{ml}$ Collagenase IV; Worthington Biochem, and $200 \mu \mathrm{g} / \mathrm{ml}$ 573 DNase I; Roche Diagnostics, in 1x PBS) was added after which the tissue was incubated at $37^{\circ} \mathrm{C}$ 574 for $45 \mathrm{~min}$. The resulting tissue suspension was then passed through a $100 \mu \mathrm{m}$ cell strainer. The 575 single-cell suspensions were incubated with rat anti-mouse CD16/32 (2.4G2; BD Biosciences) for 57610 min in FACS buffer at $4^{\circ} \mathrm{C}$ to block Fc receptors. For staining of surface antigens, cells were 
577 incubated with fluorochrome-conjugated (FITC, PE, PE-Cy7, allophycocyanin [APC], APC-eFluor

578 780,) antibodies against mouse CD45 (30-F11; BD Biosciences), Ly6C (AL-21; BD Biosciences),

579 Ly6G (1A8, BioLegend), CD11b (M1/70; eBioscience), and CD90.2 (30-H12; BioLegend). After

580 washing with FACS buffer, the cell suspension was stained with a LIVE/DEAD fluorescent dye

581 (7-AAD; BD Biosciences) for $10 \mathrm{~min}$. The stained cells were analyzed on a 2-laser LSRII flow

582 cytometer (BD Biosciences), and the data were analyzed using FACS Diva (BD Biosciences) and

583 FlowJo software (Treestar). Only single cells were analyzed, and cell numbers were quantified

584 using PE-conjugated fluorescent counting beads (Spherotech).

\section{$585 \quad$ Phagocyte killing assays}

586 The effects of gefitinib on neutrophil killing of $C$. albicans were determined by our previously described method [24]. To study human cells, neutrophils were isolated from the blood of healthy volunteers and incubated with gefitinib or diluent in RPMI 1640 medium plus $10 \%$ fetal bovine serum for $1 \mathrm{~h}$ at $37^{\circ} \mathrm{C}$. Next, the neutrophils were mixed with an equal number of serum-opsonized

of viable $C$. albicans cells was determined by quantitative culture.

To study bone marrow-derived neutrophils and macrophages (BMDMs), bone marrow top Falcon tube fitted with a $100 \mu \mathrm{m}$ filter [48]. Mouse neutrophils were purified from bone marrow cells using negative magnetic bead selection according to the manufacturer's instructions 597 (MojoSort, BioLegend). These neutrophils had $>90 \%$ purity and $>90 \%$ viability as determined by 598 flow cytometry. To isolate BMDMs, $6 \times 10^{6}$ bone marrow cells per $75 \mathrm{~cm}^{2}$ were seeded in RPMI 5991640 supplemented with 20\% FBS, $100 \mu \mathrm{g} / \mathrm{ml}$ streptomycin, $100 \mathrm{U} / \mathrm{ml}$ penicillin, $2 \mathrm{mM}$ Glutamine, 600 and $25 \mathrm{ng} / \mathrm{ml} \mathrm{rHu} \mathrm{M-CSF} \mathrm{(PeproTech).} \mathrm{After} 7$ days, the BMDMs were treated with gefitinib or the 601 diluent and then incubated with serum-opsonized C. albicans cells (multiplicity of infection 1:20) 
602 for $3 \mathrm{~h}$. Next, the BMDMs were scraped, lysed by sonication, and the number of viable C. albicans

603 cells was determined by quantitative culture.

604 Statistics

605 At least three biological replicates were performed for all in vitro experiments unless otherwise

606 indicated. Data were compared by non-parametric Mann-Whitney, or non-parametric one-way

607 Kruskal-Wallis test followed by Dunn's post-hoc using GraphPad Prism (v. 8) software. P values

$608<0.05$ were considered statistically significant.

609 Data Availability

610 All relevant data are within the manuscript and its Supporting Information files.

611

612 Acknowledgments

613

This work was supported in part by NIH grant R00DE026856 to Mark Swidergall,

614 R21Al144878 to Aaron P. Mtichell, and R01DE022600 and R01Al124566 to Scott G. Filler.

615 Michael D. Lazarus. was supported by the LA BioMed Summer Fellowship Program. The funders

616 had no role in study design, data collection and analysis, decision to publish, or preparation of the

617 manuscript. We thank the members of the Division of Infectious Diseases at Harbor-UCLA

618 Medical Center for critical suggestions. The content is solely the responsibility of the authors and

619 does not necessarily represent the official views of the National Institutes of Health.

620

621 Competing interests

622 Scott G. Filler is a co-founder of and shareholder in NovaDigm Therapeutics, Inc., a company that

623 is developing a vaccine against mucosal and invasive Candida infections. 


\section{References}

626

627

628

629

630

631

632

633

634

635

636

637

638

639

640

641

642

643

644

645

646

647

648

649

650

651

652

653

654

655

656

657

658

659

660

661

662

663

664

665

666

667

668

669

670

671

672

673

674

1. Swidergall M, Filler SG. Oropharyngeal Candidiasis: Fungal Invasion and Epithelial Cell Responses. PLoS Path. 2017;13(1):e1006056. doi: 10.1371/journal.ppat.1006056.

2. Wachtler B, Citiulo F, Jablonowski N, Forster S, Dalle F, Schaller M, et al. Candida albicans-epithelial interactions: dissecting the roles of active penetration, induced endocytosis and host factors on the infection process. PLoS ONE. 2012;7(5):14.

3. Phan QT, Myers CL, Fu Y, Sheppard DC, Yeaman MR, Welch WH, et al. Als3 is a Candida albicans invasin that binds to cadherins and induces endocytosis by host cells. PLoS Biol. 2007;5(3):e64. PubMed PMID: 17311474.

4. Sun JN, Solis NV, Phan QT, Bajwa JS, Kashleva H, Thompson A, et al. Host cell invasion and virulence mediated by Candida albicans Ssa1. PLoS Pathog. 2010;6(11):e1001181. PubMed PMID: 21085601.

5. Zhu W, Phan QT, Boontheung P, Solis NV, Loo JA, Filler SG. EGFR and HER2 receptor kinase signaling mediate epithelial cell invasion by Candida albicans during oropharyngeal infection. Proc Natl Acad Sci USA. 2012;109:14194-9. Epub 2012/08/15. doi: 10.1073/pnas.1117676109. PubMed PMID: 22891338.

6. Richardson JP, Mogavero S, Moyes DL, Blagojevic M, Kruger T, Verma AH, et al. Processing of Candida albicans Ece1p is critical for candidalysin maturation and fungal virulence. MBio. 2018;9(1):02178-17.

7. Moyes DL, Wilson D, Richardson JP, Mogavero S, Tang SX, Wernecke J, et al. Candidalysin is a fungal peptide toxin critical for mucosal infection. Nature. 2016;532(7597):648.

8. Lionakis MS, Iliev ID, Hohl TM. Immunity against fungi. JCI Insight. 2017;2(11):93156.

9. Lionakis MS, Levitz SM. Host Control of Fungal Infections: Lessons from Basic Studies and Human Cohorts. Annu Rev Immunol. 2017;13(10):042617-53318.

10. Swidergall M, Ernst JF. Interplay between Candida albicans and the antimicrobial peptide armory. Eukaryot Cell. 2014;13(8):950-7.

11. Swidergall M. Candida albicans at Host Barrier Sites: Pattern Recognition Receptors and Beyond. Pathogens (Basel, Switzerland). 2019;8(1):40. doi: 10.3390/pathogens8010040. PubMed PMID: 30934602.

12. Gladiator A, Wangler N, Trautwein-Weidner K, LeibundGut-Landmann S. Cutting edge: IL-17-secreting innate lymphoid cells are essential for host defense against fungal infection. J Immunol. 2013;190(2):521-5.

13. Verma AH, Richardson JP, Zhou C, Coleman BM, Moyes DL, Ho J, et al. Oral epithelial cells orchestrate innate type 17 responses to Candida albicans through the virulence factor candidalysin. Sci Immunol. 2017;2(17). Epub 2017/11/05. doi: 10.1126/sciimmunol.aam8834. PubMed PMID: 29101209; PubMed Central PMCID: PMCPMC5881387.

14. Conti HR, Shen F, Nayyar N, Stocum E, Sun JN, Lindemann MJ, et al. Th17 cells and IL-17 receptor signaling are essential for mucosal host defense against oral candidiasis. J Exp Med. 2009;206(2):299-311. PubMed PMID: 19204111.

15. Conti HR, Peterson AC, Brane L, Huppler AR, Hernandez-Santos N, Whibley N, et al. Oral-resident natural Th17 cells and gammadelta T cells control opportunistic Candida albicans infections. J Exp Med. 2014;211(10):2075-84.

16. Swidergall M, Solis NV, Lionakis MS, Filler SG. EphA2 is an epithelial cell pattern recognition receptor for fungal beta-glucans. Nat Microbiol. 2018;3(1):53-61.

17. Swidergall M, Solis NV, Wang Z, Phan QT, Marshall ME, Lionakis MS, et al. EphA2 Is a Neutrophil Receptor for Candida albicans that Stimulates Antifungal Activity during Oropharyngeal Infection. Cell Rep. 2019;28(2):423-33.e5. Epub 2019/07/11. doi: 10.1016/j.celrep.2019.06.020. PubMed PMID: 31291578; PubMed Central PMCID: PMCPMC6638578. 
18. Ho J, Yang X, Nikou SA, Kichik N, Donkin A, Ponde NO, et al. Candidalysin activates innate epithelial immune responses via epidermal growth factor receptor. Nat Commun. 2019;10(1):2297. Epub 2019/05/28. doi: 10.1038/s41467-019-09915-2. PubMed PMID: 31127085; PubMed Central PMCID: PMCPMC6534540.

19. Sabet O, Stockert R, Xouri G, Bruggemann Y, Stanoev A, Bastiaens PI. Ubiquitination switches EphA2 vesicular traffic from a continuous safeguard to a finite signalling mode. Nat Commun. 2015;6(8047).

20. Stallaert W, Brüggemann Y, Sabet O, Baak L, Gattiglio M, Bastiaens PIH. Contact inhibitory Eph signaling suppresses EGF-promoted cell migration by decoupling EGFR activity from vesicular recycling. Science Signaling. 2018;11(541). doi: 10.1126/scisignal.aat0114. 21. Larsen AB, Pedersen MW, Stockhausen MT, Grandal MV, van Deurs B, Poulsen HS. Activation of the EGFR gene target EphA2 inhibits epidermal growth factor-induced cancer cell motility. Mol Cancer Res. 2007;5(3):283-93.

22. Barker AJ, Gibson KH, Grundy W, Godfrey AA, Barlow JJ, Healy MP, et al. Studies leading to the identification of ZD1839 (IRESSA): an orally active, selective epidermal growth factor receptor tyrosine kinase inhibitor targeted to the treatment of cancer. Bioorg Med Chem Lett. 2001;11(14):1911-4. Epub 2001/07/19. doi: 10.1016/s0960-894x(01)00344-4. PubMed PMID: 11459659.

23. Zhu W, Phan QT, Boontheung P, Solis NV, Loo JA, Filler SG. EGFR and HER2 receptor kinase signaling mediate epithelial cell invasion by Candida albicans during oropharyngeal infection. Proc Natl Acad Sci U S A. 2012;109(35):14194-9.

24. Solis NV, Swidergall M, Bruno VM, Gaffen SL, Filler SG. The Aryl Hydrocarbon Receptor Governs Epithelial Cell Invasion during Oropharyngeal Candidiasis. MBio. 2017;8(2):00025-17. 25. Dickson MA, Hahn WC, Ino Y, Ronfard V, Wu JY, Weinberg RA, et al. Human keratinocytes that express hTERT and also bypass a p16(INK4a)-enforced mechanism that limits life span become immortal yet retain normal growth and differentiation characteristics. Mol Cell Biol. 2000;20(4):1436-47. PubMed PMID: 10648628.

26. Schonherr FA, Sparber F, Kirchner FR, Guiducci E, Trautwein-Weidner K, Gladiator A, et al. The intraspecies diversity of $C$. albicans triggers qualitatively and temporally distinct host responses that determine the balance between commensalism and pathogenicity. Mucosal Immunol. 2017;8(10):2.

27. Fu Y, Rieg G, Fonzi WA, Belanger PH, Edwards JE, Jr., Filler SG. Expression of the Candida albicans gene ALS1 in Saccharomyces cerevisiae induces adherence to endothelial and epithelial cells. Infect Immun. 1998;66(4):1783-6.

28. Verma A, Gaffen SL, Swidergall M. Innate immunity to mucosal Candida infections. J Fungi. 2017;3(4).

29. Naglik JR, Moyes D. Epithelial Cell Innate Response to Candida albicans. Adv Dental Res. 2011;23(1):50-5. doi: 10.1177/0022034511399285. PubMed PMID: PMC3144045.

30. Amato KR, Wang S, Tan L, Hastings AK, Song W, Lovly CM, et al. EPHA2 Blockade Overcomes Acquired Resistance to EGFR Kinase Inhibitors in Lung Cancer. Cancer Res. 2016;76(2):305-18. Epub 2016/01/09. doi: 10.1158/0008-5472.Can-15-0717. PubMed PMID: 26744526; PubMed Central PMCID: PMCPMC4715957.

31. Koch H, Busto ME, Kramer K, Medard G, Kuster B. Chemical Proteomics Uncovers EPHA2 as a Mechanism of Acquired Resistance to Small Molecule EGFR Kinase Inhibition. J Proteome Res. 2015;14(6):2617-25. Epub 2015/05/13. doi: 10.1021/acs.jproteome.5b00161. PubMed PMID: 25963923.

32. Filler SG, Swerdloff JN, Hobbs C, Luckett PM. Penetration and damage of endothelial cells by Candida albicans. Infect Immun. 1995;63(3):976-83.

33. Staab JF, Bradway SD, Fidel PL, Sundstrom P. Adhesive and mammalian transglutaminase substrate properties of Candida albicans Hwp1. Science. 1999;283(5407):1535-8. 
762

763

764

765

766

767

768

769

770

771

772

773

774

775

34. Swidergall M, Khalaji M, Solis NV, Moyes DL, Drummond RA, Hube B, et al. Candidalysin Is required for neutrophil recruitment and virulence during systemic Candida albicans infection. J Infect Dis. 2019;220(9):1477-88. Epub 2019/08/12. doi:

10.1093/infdis/jiz322. PubMed PMID: 31401652; PubMed Central PMCID: PMCPMC6761979. 35. Drummond RA, Swamydas M, Oikonomou V, Zhai B, Dambuza IM, Schaefer BC, et al. CARD9(+) microglia promote antifungal immunity via IL-1 $\beta$ - and CXCL1-mediated neutrophil recruitment. Nat Immunol. 2019;20(5):559-70. Epub 2019/04/19. doi: 10.1038/s41590-0190377-2. PubMed PMID: 30996332; PubMed Central PMCID: PMCPMC6494474.

36. Altmeier S, Toska A, Sparber F, Teijeira A, Halin C, LeibundGut-Landmann S. IL-1 coordinates the neutrophil response to $C$. albicans in the oral mucosa. PLoS Pathog. $2016 ; 12(9)$.

37. Min K, Ichikawa Y, Woolford CA, Mitchell AP. Candida albicans Gene Deletion with a Transient CRISPR-Cas9 System. mSphere. 2016;1(3). Epub 2016/06/25. doi: 10.1128/mSphere.00130-16. PubMed PMID: 27340698; PubMed Central PMCID: PMCPMC4911798.

38. Huang MY, Woolford CA, May G, McManus CJ, Mitchell AP. Circuit diversification in a biofilm regulatory network. PLoS Pathog. 2019;15(5):e1007787. Epub 2019/05/23. doi: 10.1371/journal.ppat.1007787. PubMed PMID: 31116789; PubMed Central PMCID: PMCPMC6530872.

39. Frazer C, Hernday AD, Bennett RJ. Monitoring Phenotypic Switching in Candida albicans and the Use of Next-Gen Fluorescence Reporters. Curr Protoc Microbiol. 2019;53(1):e76. Epub 2019/02/13. doi: 10.1002/cpmc.76. PubMed PMID: 30747494.

40. Huang MY, Mitchell AP. Marker Recycling in Candida albicans through CRISPR-Cas9Induced Marker Excision. MSphere. 2017;2(2). Epub 2017/03/21. doi: 10.1128/mSphere.0005017. PubMed PMID: 28317025; PubMed Central PMCID: PMC5352831.

41. Vyas VK, Barrasa MI, Fink GR. A Candida albicans CRISPR system permits genetic engineering of essential genes and gene families. Sci Adv. 2015;1(3):e1500248. Epub 2015/05/16. doi: 10.1126/sciadv.1500248. PubMed PMID: 25977940; PubMed Central PMCID: PMC4428347.

42. Walther A, Wendland J. An improved transformation protocol for the human fungal pathogen Candida albicans. Curr Genet. 2003;42(6):339-43. Epub 2003/03/04. doi: 10.1007/s00294-002-0349-0. PubMed PMID: 12612807.

43. Conti HR, Bruno VM, Childs EE, Daugherty S, Hunter JP, Mengesha BG, et al. IL-17 Receptor Signaling in Oral Epithelial Cells Is Critical for Protection against Oropharyngeal Candidiasis. Cell Host Microbe. 2016;20(5):606-17.

44. Solis NV, Park YN, Swidergall M, Daniels KJ, Filler SG, Soll DR. Candida albicans White-Opaque Switching Influences Virulence but Not Mating during Oropharyngeal Candidiasis. Infect Immun. 2018;86(6). Epub 2018/03/28. doi: 10.1128/iai.00774-17. PubMed PMID: 29581190; PubMed Central PMCID: PMCPMC5964503.

45. Solis NV, Filler SG. Mouse model of oropharyngeal candidiasis. Nat Protoc. 2012;7(4):637-42.

46. Break TJ, Jaeger M, Solis NV, Filler SG, Rodriguez CA, Lim JK, et al. CX3CR1 is dispensable for control of mucosal Candida albicans infections in mice and humans. Infect Immun. 2015;83(3):958-65.

47. Sparber F, LeibundGut-Landmann S. Assessment of Immune Responses to Fungal Infections: Identification and Characterization of Immune Cells in the Infected Tissue. Methods Mol Biol. 2017:167-82.

48. Swamydas M, Luo Y, Dorf ME, Lionakis MS. ISOLATION OF MOUSE NEUTROPHILS. Current protocols in immunology / edited by John E Coligan [et al]. 2015;110:3.20.1-3..15. doi: 10.1002/0471142735.im0320s110. PubMed PMID: PMC4574512. 

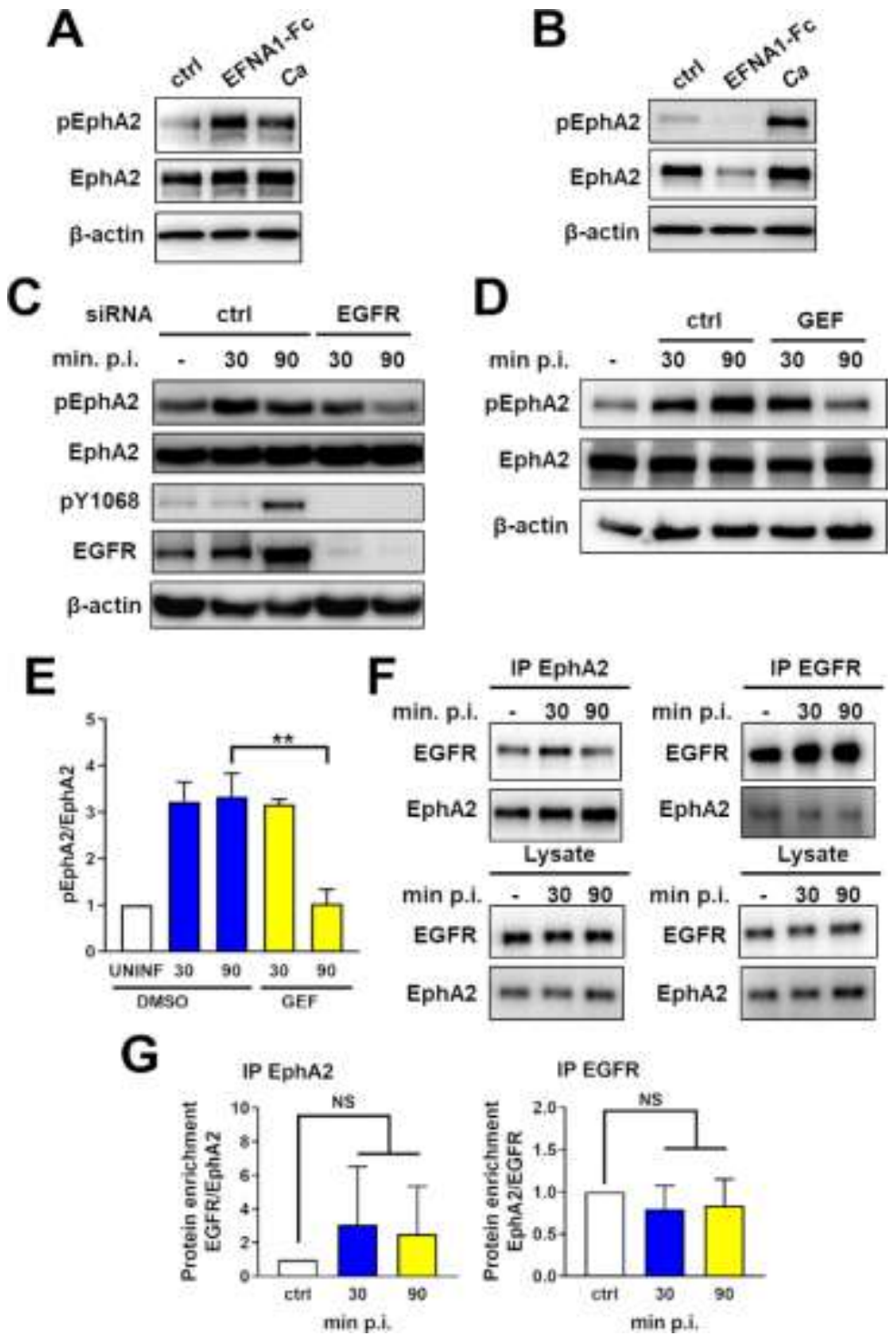

Fig 1. EGFR activity is required for sustained EphA2 phosphorylation. (A and $B$ ) Immunoblots showing effects of ephrin A1-Fc (EFNA1-Fc) or yeast-phase C. albicans SC5314 (Ca) on the phosphorylation of ephrin type-A receptor 2 (EphA2) in OKF6/TERT-2 oral epithelial cells after stimulation for $15 \mathrm{~min}(\mathrm{~A})$ and $60 \mathrm{~min}(\mathrm{~B})$ post-infection (p. i.). Results are representative of 3 independent experiments. Densitometric quantification of all 3 immunoblots is shown in $\mathrm{S} 1$ Fig. (C and D) Effects of epidermal growth factor (EGFR) siRNA (C) and the EGFR kinase inhibitor gefitinib (GEF) (D) on the time course of EphA2 and EGFR phosphorylation in oral epithelial cells infected with $C$. albicans. Results are representative of 3 independent experiments. Densitometric quantification of all 3 immunoblots such as the one in Fig. $1 \mathrm{C}$ is shown in S1 Fig. (E) Densitometric quantification of all 3 immunoblots such as the one in Fig. 3D. (F) Lysates of oral epithelial cells infected with $C$. albicans for 30 and 90 min were immunoprecipitated (IP) with antibodies against EphA2 (left) and EGFR (right), after which EphA2 and EGFR were detected by immunoblotting (Top). Immunoblots of lysates prior to immunoprecipitation, demonstrating equal amounts of input protein (Bottom). (G) Densitometric analysis of 3 independent immunoblots such as the ones shown in $(F)$. Results are mean \pm SD. Statistical significance relative to uninfected control cells was analyzed by the Student's t test assuming unequal variances. ${ }^{* *}, p<0.01$; NS, not significant. 
A

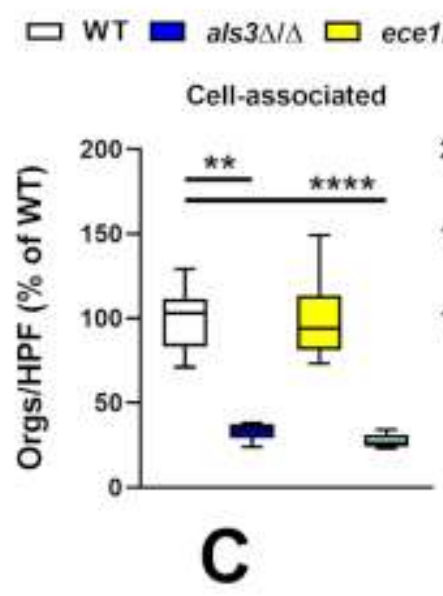

B


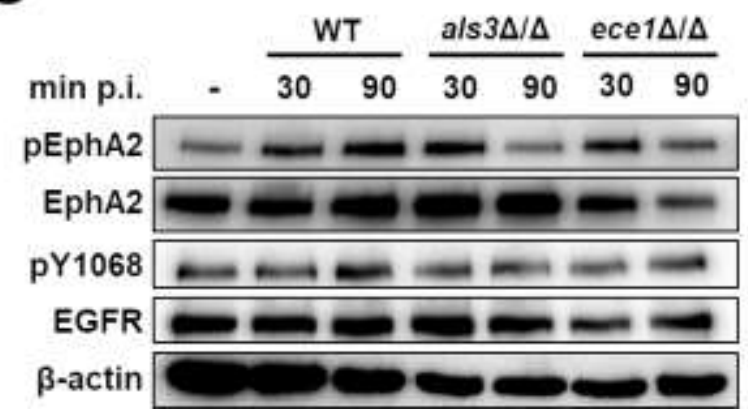

Fig 2. Effects of $C$. albicans als $3 \Delta / \Delta$ and ece1 $\Delta / \Delta$ mutants EGFR and EphA2 activation. (A) The number of cell-associated (a measure of adherence) and endocytosed organisms (orgs) per high-power field (HPF) of the indicated C. albicans strains after 120 min of infection of OKF6/TERT-2 oral epithelial cells. (B) Extent of epithelial cell damage caused by the indicated strains after $8 \mathrm{~h}$ of infection. Data in (A and B) are the combined results of three experiments, each performed in triplicate. Statistical significance was determined by analysis of variance with Dunnett's test for multiple comparisons. ${ }^{* *}, p<0.01$; $^{* * *}, p<0.001$; $^{* * *}, p<0.0001$. (C) Immunoblot analysis showing the effects of the indicated $C$. albicans strains on the phosphorylation of EphA2 and EGFR after 30 and 90 min post-infection (p. i.). Result are representative a 3 independent experiments. Densitometric quantification of all 3 immunoblots such as the one in Fig. $3 \mathrm{C}$ is shown in S2 Fig. 


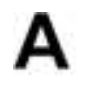

ctrl siRNA $\square$ EGFR siRNA $\square$ EphA2 siRNA

CXCL8/IL-8

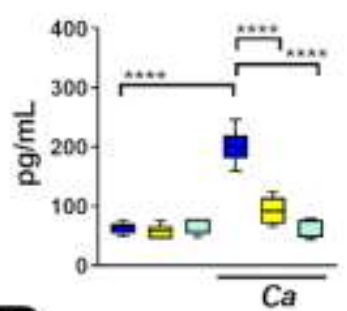

CCL20

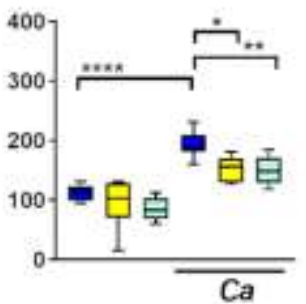

IL-1 $\alpha$

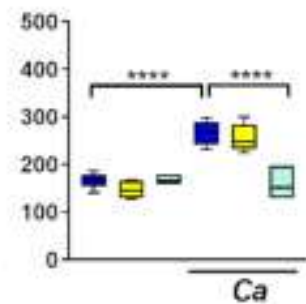

IL-1 $\beta$

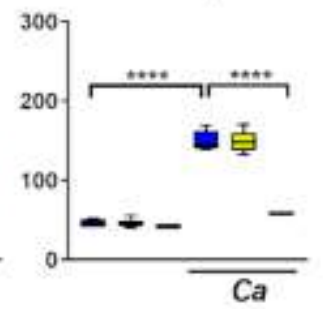

B

$\square$ ctrl $\square$ GEF

CXCL8/IL-8
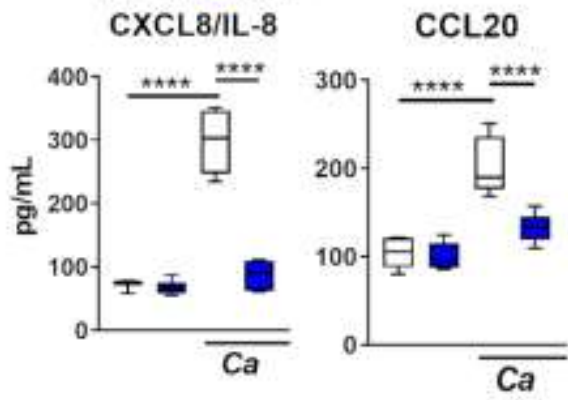

$\mathrm{IL}-1 \alpha$

IL-1 $\beta$
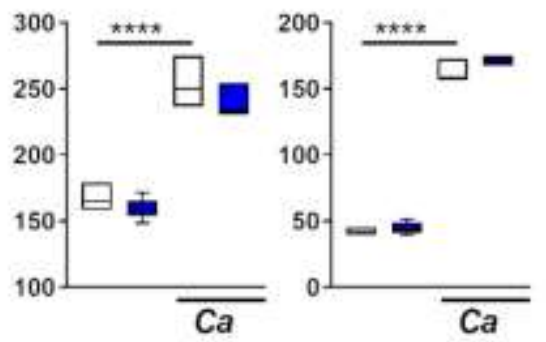

C

$\square$ UNINF $\square$ WT $\square$ als $3 \Delta / \Delta \square$ ece1 $\Delta / \Delta \square$ als3 $/ \Delta$ ece1 $\Delta / \Delta$

CXCL8/IL-8
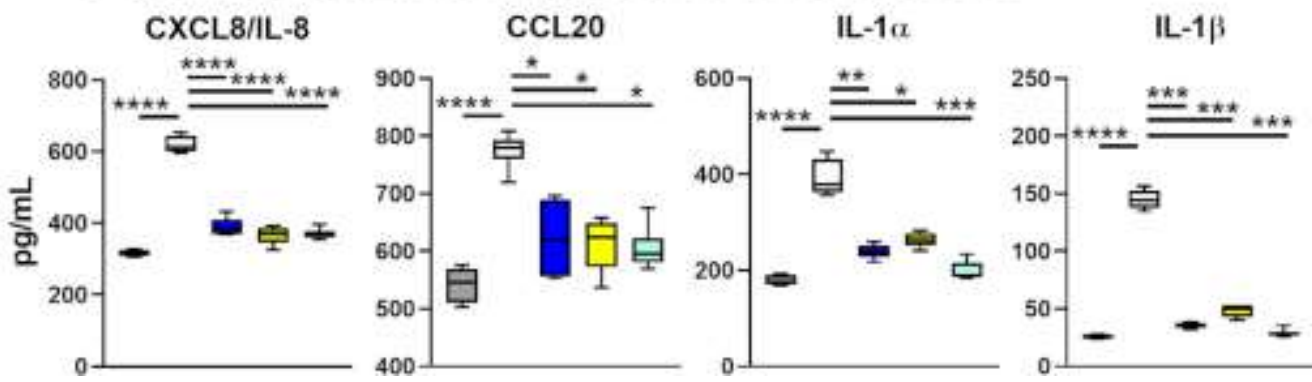

Fig 3. EGFR signaling is required to induce a subset of epithelial cells inflammatory responses in vitro. (A) Effects of siRNA knockdown of EGFR and EphA2 on the production of the indicated cytokines and chemokines by OKF6/TERT-2 oral epithelial cell in response to $8 \mathrm{~h}$ of infection with C. albicans. (B) Effects of the EGFR inhibitor gefitinib on the epithelial cell response to $C$. albicans. (C) Stimulation of epithelial cells by the indicated strains of $C$. albicans. Box whisker plots show median, interquartile range, and range of 3 independent experiments, each performed in duplicate. The data were analyzed using the Kruskal-Wallis corrected for multiple comparisons. ${ }^{*}, p<0.05 ;{ }^{* *}, p<0.01 ;{ }^{* * *}, p<0.001 ;{ }^{* * *} p,<0.0001 ; \mathrm{Ca}, \mathrm{C}$. albicans; ctrl, control; GEF, gefitinib. 
A



ロTR146 口 OKF6/TERT-2



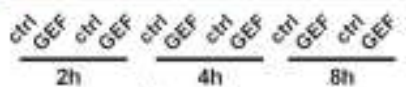

E

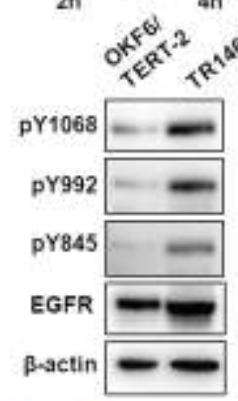

G

ㅁ ctrl ש GEF

B



(1)

D $\square$ TR146

ロ OKFEITERT-2

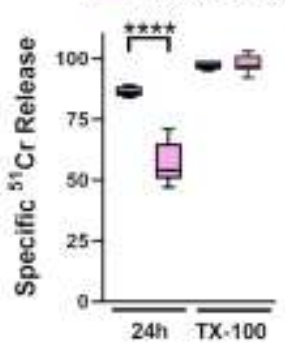

F

baseline cytokines




Fig 4. Comparison of the response of two oral epithelial cell lines to $\boldsymbol{C}$. albicans infection and EGFR inhibition. (A) Adherence and endocytosis of wild-type $C$. albicans by OKF6/TERT-2 and TR146 oral epithelial cell lines. (B) Comparison of the effects of gefitinib (GEF) on C. albicans adherence to and endocytosis by OKF6-TERT-2 and TR146 cells. (C) Time course of $C$. albicansinduced damage to OKF6-TERT-2 and TR146 cells. (D) Extent of damage to OKF6-TERT-2 and TR146 cells caused by $C$. albicans and Triton X-100 after $24 \mathrm{~h}$ incubation. (E) Comparison of the extent of phosphorylation on the indicated tyrosine residues of EGFR phosphorylation in unstimulated OKF6/TERT-2 and TR146 cells. Shown in a representative immunoblot from 3 independent experiments. (F) Comparison of the basal release of the indicated inflammatory mediators by uninfected OKF6-TERT-2 and TR146 cells. Results are the ratio of TR146 cells to OKF6/TERT2 cells. (G) Effects of gefitinib on C. albicans-induced production of the indicated pro- 
828 inflammatory mediators by TR146 cells. Graphs show the results of 3 experiments, each 829 performed in triplicate $(A-D)$ or duplicate $(F$ and $G)$. The data in $(A, B$, and $D)$ were analyzed with 830 the Mann-Whitney test, and the data in $(C$ and $G)$ were analyzed by the Kruskal-Wallis test 831 corrected for multiple comparisons. ${ }^{*}, p<0.05 ;{ }^{* *}, p<0.01 ;{ }^{* *}, p<0.001 ;{ }^{* \star *} p,<0.0001 ; \mathrm{Ca}, \mathrm{C}$. 832 albicans; ctrl, control; GEF, gefitinib; TX-100, Triton X-100. 
A


B

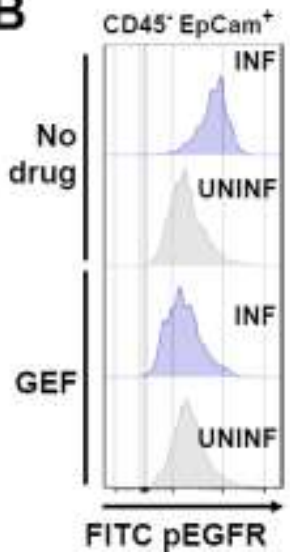

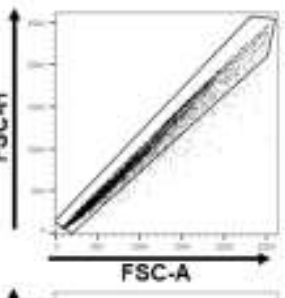



PE EpCam

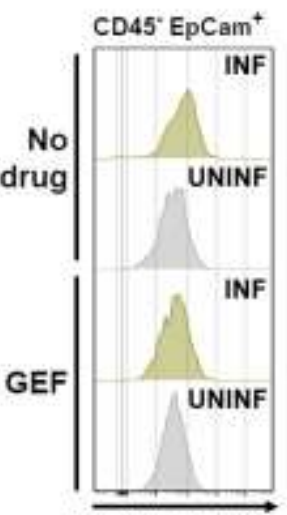

FITC PEphA2
C


PEGFR

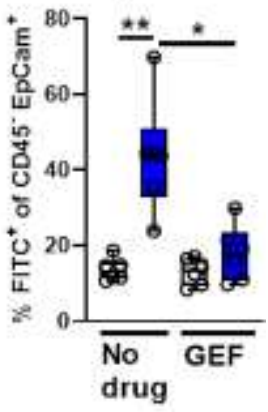

D
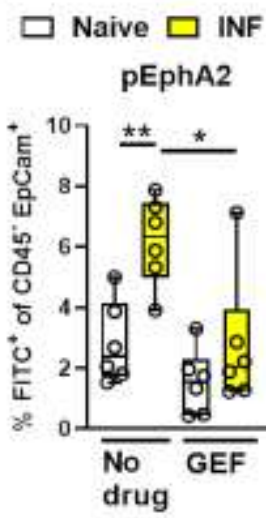

Fig 5. Pharmacological inhibition of EGFR reduces $C$. albicans-induced EphA2 activation during OPC. (A) Gating strategy to determine EGFR and EphA2 phosphorylation in the oral epithelial cells of mice with OPC. (B) Representative histograms of CD45- EpCam+ cells showing the effects of $C$. albicans infection and gefitinib (GEF) treatment on the phosphorylation of EGFR and EphA2 after $1 \mathrm{~d}$ of OPC. (C-D) Effects of gefitinib on the percentage of oral epithelial cells with phosphorylated EGFR (C) and EphA2 (D) in mice after $1 \mathrm{~d}$ of OPC. Data are combined results from 6 mice per group from a single experiment. Statistical significance was determined using the Mann-Whitney test. ${ }^{*}, p<0.05 ;{ }^{* *}, p<0.01$; INF, infected; UNINF, uninfected. 


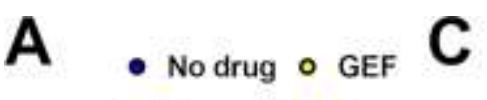

Oral Fungal Burden


D
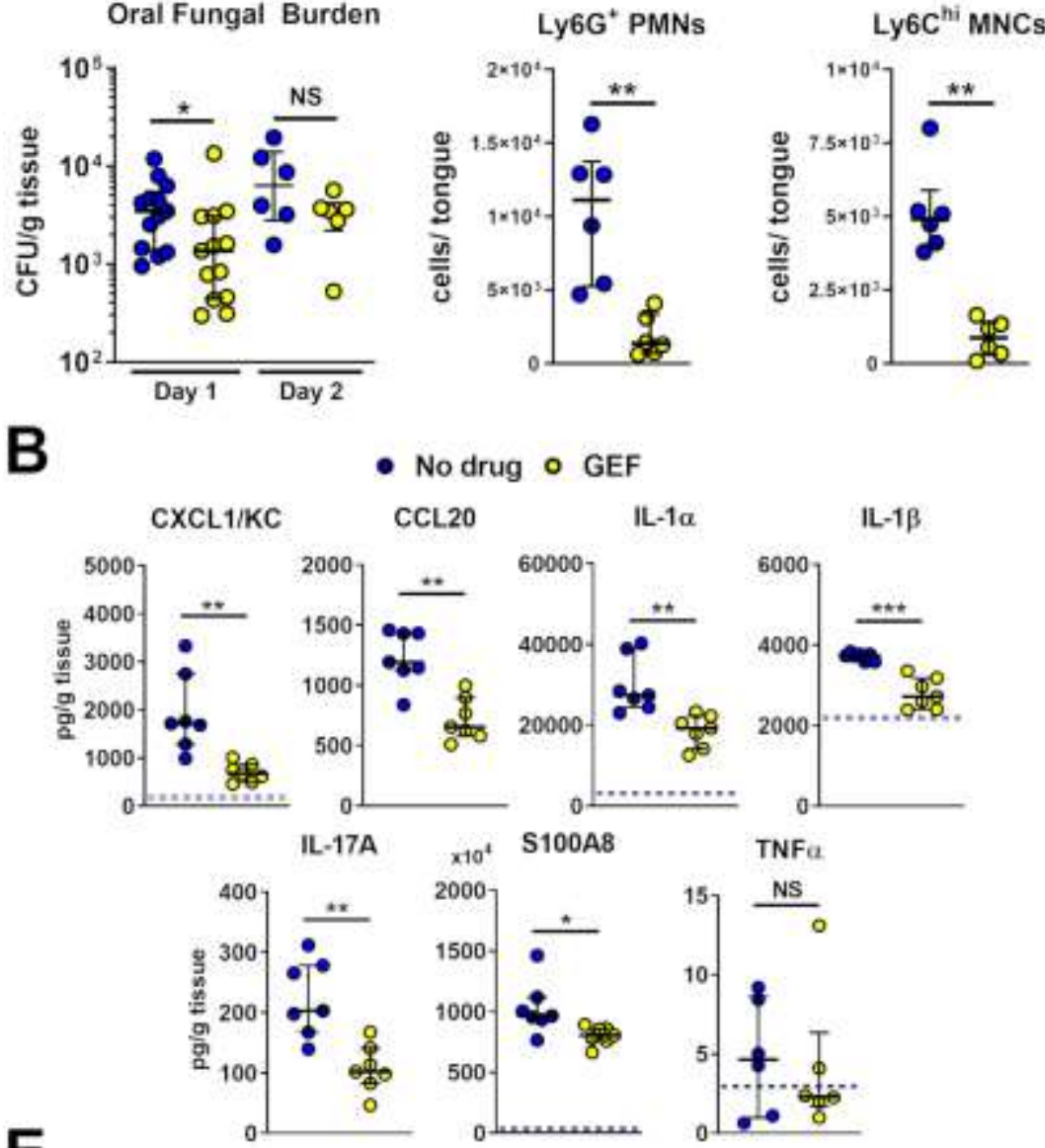

E

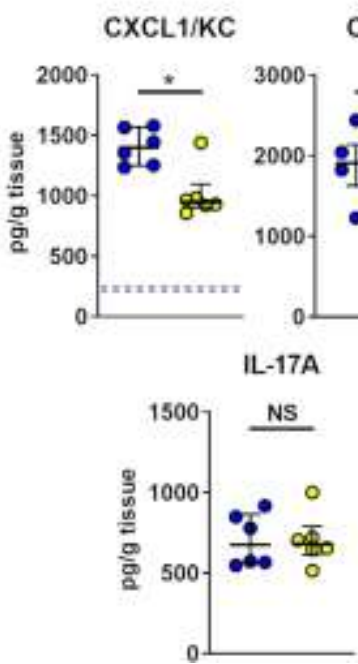

CCL20
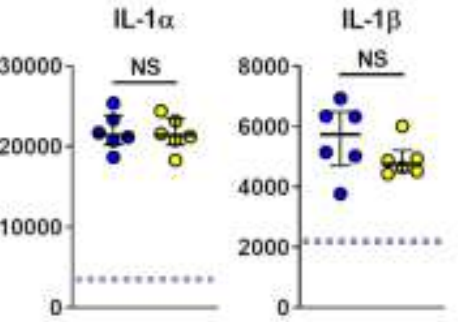

Fig 6. Pharmacological inhibition of EGFR decreases early fungal burden and reduces the inflammatory response. (A) Oral fungal burden of control (no drug) and gefitinib (GEF) treated mice after 1 and $2 \mathrm{~d}$ post-infection. Results are the median \pm interquartile range of at total of 14 mice per group from two independent experiments on $\mathrm{d} 1$ and of a total of 6 mice per group from 
850 (E) of infection. Results are from at total of 7 mice per group from two independent experiments 851 on $\mathrm{d} 1$ and from a total of 6 mice per group from a single experiment on d 2. Dashed line indicates 852 the median level of inflammatory mediators in uninfected mice if above 0 . ( $C$ and $D)$ Levels of 853 neutrophils (C) and inflammatory monocytes (D) in the tongues of control and gefitinib-treated 854 mice after $1 \mathrm{~d}$ of infection. Results are from a total of 6 mice per group from two independent 855 experiments. Statistical significance in (A, C and D) was determined using the Mann-Whitney test 856 and in (B and $\mathrm{E}$ ) by the Kruskal-Wallis test corrected for multiple comparisons. NS, not significant; $857 \quad{ }^{*}, p<0.05 ;{ }^{* *}, p<0.01$. 


\section{A}

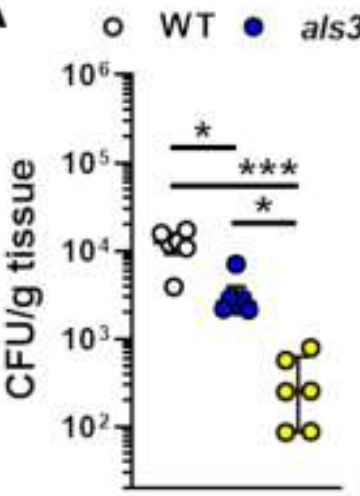

Day 1

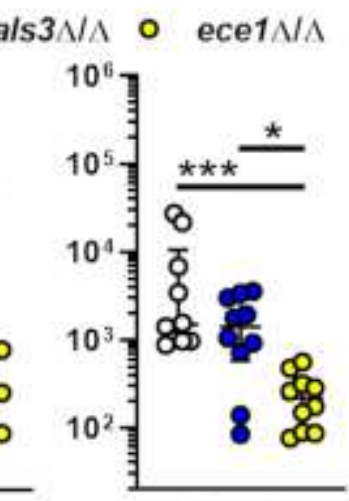

Day 2

B
- WT O als1 $/ \mathrm{A}$ als $3 \mathrm{~N} / \mathrm{A}$
- als1A/A O ece1 $\Delta / \Delta$
- als1 $/ / \Delta a / s 3 \mathrm{~N} / \mathrm{Aece} 1 \mathrm{~N} / \mathrm{A}$



Day 1



Day 2
860

861

862

863

864

865

866

Fig 7. Roles of Als1, Als3, Ece1/Candidalysin in C. albicans virulence during OPC. (A and B) Oral fungal burden of Balb/c mice 1 and $2 \mathrm{~d}$ after inoculation with the indicated strains of $C$. albicans. Results are the median \pm interquartile range of 6-8 mice per strain from single experiments, except for $d 2$ of in (A), which are from a total of 10 mice from 2 independent experiments. The data were analyzed by the Kruskal-Wallis test corrected for multiple comparisons. ${ }^{*}, p<0.05 ;{ }^{* *}, p<0.01 ;{ }^{* * *}, p<0.001$. 

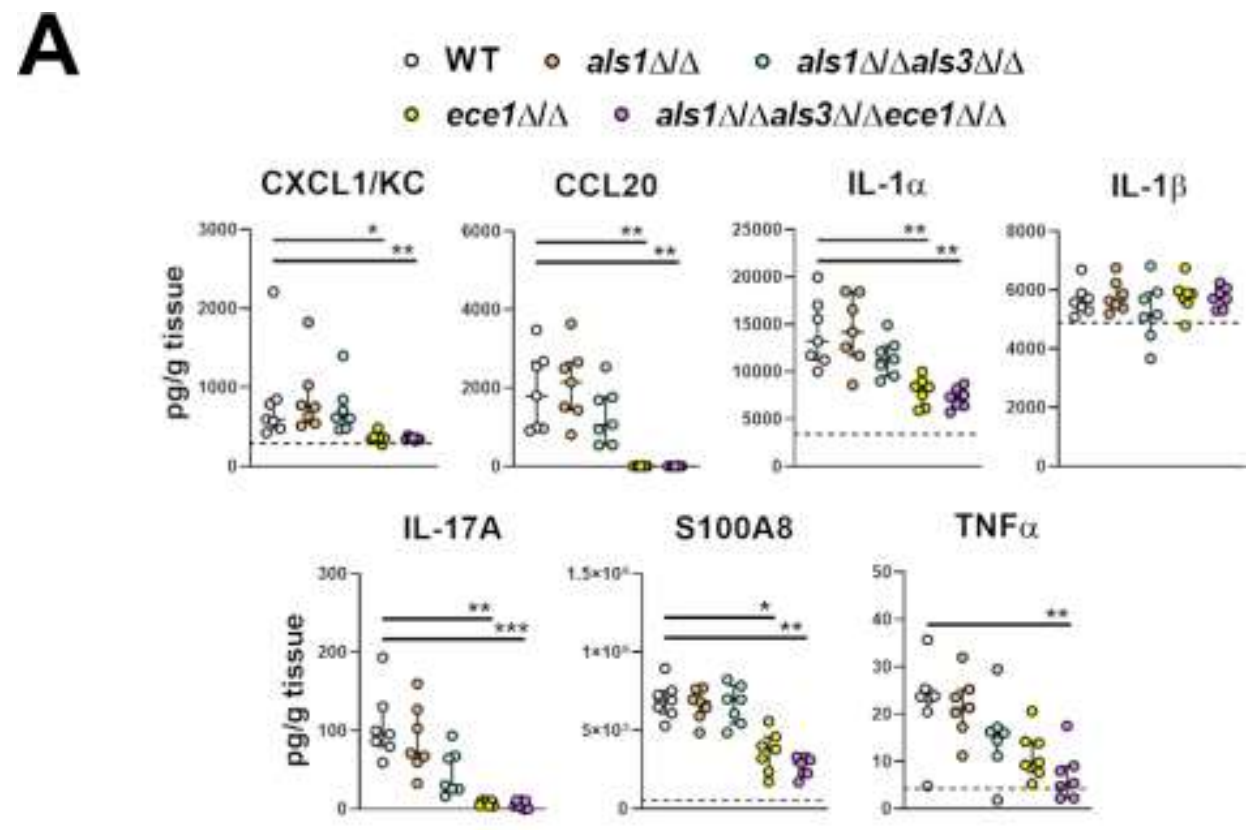

B

- WT $\circ$ als1N/A $\circ$ als1NAals3NA

- ece1NA ○ als1N/Aals3NAece1NA

\section{CXCL1/KC IL-1 $\alpha$ IL-1 $\beta$}

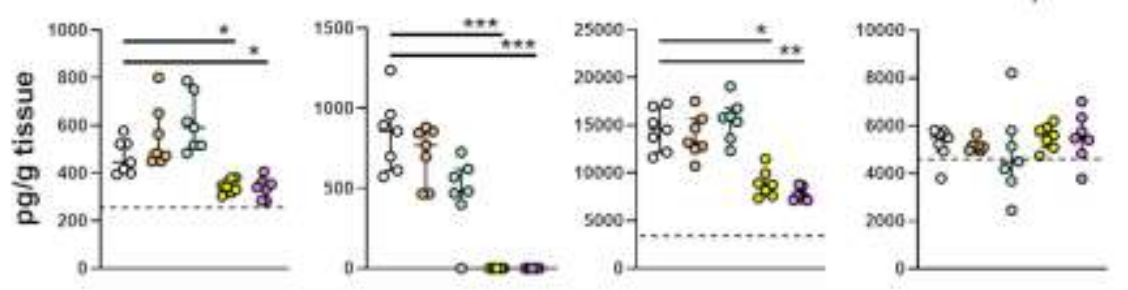

869 Fig 8. Induction of the oral inflammatory response by $C$. albicans invasins and 870 Ece1/Candidalysin. Levels of the indicated inflammatory mediators in the tongues of mice orally 871 inoculated with indicated strains of $C$. albicans after $1 \mathrm{~d}(\mathrm{~A})$ and $2 \mathrm{~d}(\mathrm{~B})$ of infection. Results are 872 the median \pm interquartile range of a total of 7 mice in each group from a single experiment. 873 Median levels of inflammatory mediators in uninfected mice are indicated with dashed line if above 874 0. The data were analyzed by the Kruskal-Wallis test corrected for multiple comparisons. $875 \quad{ }^{*}, p<0.05 ;{ }^{* *}, p<0.01 ;{ }^{* *}, p<0.001$. 